\title{
Influence of exogenous fibrolytic enzymes and fumarate on methane production, microbial growth and fermentation in Rusitec fermenters
}

\author{
L. A. Giraldo ${ }^{1,2}$, M. J. Ranilla ${ }^{1}$, M. L. Tejido ${ }^{1}$ and M. D. Carro ${ }^{1 *}$ \\ ${ }^{1}$ Departamento de Producción Animal I. Universidad de León, 24071León, Spain \\ ${ }^{2}$ Universidad Nacional de Colombia, Sede Medellín, Facultad de Ciencias Agropecuarias, Colombia \\ (Received 5 December 2006 - Revised 23 March 2007 - Accepted 29 March 2007)
}

Two incubation runs were conducted with Rusitec fermenters to investigate the effects of three additive treatments (mixed fibrolytic enzymes from Trichoderma longibrachiatum (FE), disodium fumarate (FUM) and both additives (MIX)) on rumen microbial growth and fermentation of a grass hay:concentrate $(600: 400 \mathrm{~g} / \mathrm{kg} \mathrm{DM})$ substrate. Each fermenter received daily $20 \mathrm{~g}$ substrate DM. Application rate (per g substrate DM) was $34 \cdot 3$ endoglucanase, 0.57 exoglucanase, 24.7 xylanase and 5.51 amylase units for FE and $30 \mathrm{mg}$ fumarate for FUM. MIX fermenters received both additives. Both FE and MIX increased $(P<0.05)$ daily production of acetate, butyrate and methane, substrate DM and fibre disappearance at 6 and $48 \mathrm{~h}$ incubation, daily flow of microbial-N, and the microbial colonisation of substrate at $6 \mathrm{~h}$ incubation. Compared to FE, MIX treatment increased $(P<0.05)$ propionate production by $28 \%$ and decreased $(P<0.05)$ the acetate:propionate ratio, but no other differences between both treatments were found $(P>0.05)$. Supplementing with FUM increased $(P<0.05)$ volatile fatty acid production by $11 \%$ and decreased $(P<0.05)$ the acetate:propionate ratio, but did not affect $(P>0.05)$ any other variable, thus suggesting that observed effects were due to fermentation of FUM itself. The lack of effects of FUM and the absence of differences between FE and MIX on most of the measured variables would indicate that beneficial effects found in MIX fermenters were mainly due to the action of FE. Combining FE and FUM as feed additives under the conditions of the present experiment did not further improve rumen fermentation, compared to FE alone.

Fibrolytic enzymes: Fumarate: Rumen microbial growth: Rusitec

The use of fibrolytic enzymes (e.g. cellulases, xylanases) as feed additives for ruminants has been viewed with considerable scepticism for a long time, but in recent years has received increasing interest. Despite the considerable number of studies conducted recently on this topic, the mechanisms by which fibrolytic enzymes improve fibre digestion in the rumen have not been clearly elucidated, and seem to be affected by different factors, such as the type of enzyme used and the nature of the substrate ${ }^{1,2}$. Treating forage-based substrates with fibrolytic enzymes has been reported to enhance fibre degradability and production of volatile fatty acids (VFA) in vitro, but also to increase methane production $^{3-5}$. Because methane represents a significant loss of energy for the host animal and contributes to global warming ${ }^{6}$, reducing methane production is an important goal of ruminant nutritionists and a range of chemical compounds such as methane analogues, ionophores and unsaturated fatty acids have been tested as potential feed additives to depress rumen methanogenesis. However, some of these compounds simultaneously produce adverse effects on rumen fermentation, such as a depression of fibre degradation or reduction of microbial growth ${ }^{7}$. Conversely, fumarate has been shown to produce a decrease in methane production accompanied by an increase in both the production of
VFA and diet degradation ${ }^{8-10}$. Our hypothesis was that fumarate and exogenous fibrolytic enzymes could act synergistically to improve rumen fermentation. The objective of this study was therefore to investigate the effects of mixed fibrolytic enzymes from fungal origin, fumarate and a 1:1 mixture of both additives on rumen fermentation of a $0 \cdot 6: 0 \cdot 4$ forage:concentrate substrate, methane production and microbial growth in Rusitec fermenters. The enzyme preparation used in this study and the doses of application were selected from previous work ${ }^{5}$. The enzymes were shown to increase substrate degradability and production of VFA and methane in batch cultures of mixed rumen microorganisms fermenting high-forage substrates. The experimental procedure was designed to investigate some of the mechanisms of action proposed for exogenous fibrolytic enzymes.

\section{Materials and methods \\ Apparatus and experimental treatments}

The unit of Rusitec ${ }^{11}$ consisted of eight fermenters with an effective volume of $600 \mathrm{ml}$ each. Solid and liquid fermentation inocula were collected from four rumen-cannulated sheep

Abbreviations: ADF(D), acid detergent fibre (disappearance); CON, control treatment, no additive; DMD, dry matter disappearance; FE, mixed fibrolytic enzymes from Trichoderma longibrachiatum; FUM, disodium fumarate; LAM, liquid-associated microbial pellets; MIX, experimental treatment with both additives (FE and FUM); NAN, non-ammonia N; NDF(D), neutral detergent fibre (disappearance); SAM, solid-associated micro-organisms; VFA, volatile fatty acids.

* Corresponding author: Dr M. D. Carro, fax +34 987 291311, email mdcart@unileon.es 
immediately before feeding and transferred to the fermenters within $30 \mathrm{~min}$ as previously described ${ }^{12}$. Sheep were fed the same diet fed to fermenters and managed according to the protocols approved by the León University Institutional Animal Care and Use Committee. The flow through the fermenters was maintained by continuous infusion of artificial saliva ${ }^{13}$ $(\mathrm{pH} 8.4)$ at a rate of $580 \mathrm{ml} / \mathrm{d}$ (dilution rate $4.03 \%$ per $\mathrm{h}$ ).

Each fermenter received daily $20 \mathrm{~g} \mathrm{DM}$ substrate fed into nylon bags $(100 \mu \mathrm{m}$ pore size). The substrate consisted of grass hay and concentrate (600 and $400 \mathrm{~g} / \mathrm{kg} \mathrm{DM}$, respectively), and contained $939 \mathrm{~g}$ organic matter, $159 \mathrm{~g}$ crude protein, $496 \mathrm{~g}$ neutral detergent fibre (NDF) and $271 \mathrm{~g}$ acid detergent fibre (ADF)/kg DM. Concentrate was based on barley, maize grain, soyabean meal and mineral/vitamin premix in the proportions of 500:310:160:30 (air-dry basis). Grass hay was chopped to about $0.5 \mathrm{~cm}$ pieces and concentrate was ground through a $4 \mathrm{~mm}$ sieve. Both feed components were weighed independently and carefully mixed before applying the experimental treatments.

The four experimental treatments were: no additive (control; CON), mixed fibrolytic enzymes produced by Trichoderma longibrachiatum (FE), disodium fumarate (FUM; Sigma-Aldrich Química, S.A., Madrid, Spain) and treatment with both additives (MIX). The enzyme preparation was a powdered preparation commercialised by Fluka Chemicals (Seelze, Germany) and was previously characterised ${ }^{5}$. At $\mathrm{pH}$ 6.5 and $39^{\circ} \mathrm{C}, 1 \mathrm{mg}$ enzyme liberated $1.72 \mu \mathrm{mol}$ xylose $/ \mathrm{min}$ from oat spelt xylan, and 2.40, 0.040 and $0.385 \mu \mathrm{mol}$ glucose/min from carboxymethylcellulose, Avicel PH-101 and soluble starch, respectively. One enzymatic unit was defined as the amount of enzyme required to release $1 \mu \mathrm{mol} / \mathrm{min}$ reducing xylose or glucose from the corresponding substrate at $39^{\circ} \mathrm{C}$ and $\mathrm{pH} 6 \cdot 5$. Each fermenter received $286 \mathrm{mg}$ enzyme daily, which corresponded to $34 \cdot 3,0.57,24.7$ and 5.51 endoglucanase, exoglucanase, xylanase and amylase units, respectively, per $\mathrm{g}$ substrate DM. The enzyme preparation was dissolved daily in a sodium phosphate buffer solution (1 mM; $\mathrm{pH}$ 6.5) and carefully applied directly onto the substrate ( $1 \mathrm{ml} / \mathrm{g}$ DM) using a manual sprayer. After spraying, the substrate was kept at room temperature $\left(21-23^{\circ} \mathrm{C}\right)$ for $24 \mathrm{~h}$ before being placed into nylon bags and fed to fermenters. This pretreatment of substrate with the enzyme preparation was selected because previous studies ${ }^{1,14}$ showed that an enzyme-feed interaction before incubation with rumen fluid can enhance the beneficial effects of enzymes on rumen fermentation. Substrate for CON and FUM fermenters was sprayed with the corresponding amount of buffer solution without added enzyme preparation. Fermenters belonging to FUM and MIX treatments were supplemented daily with $30 \mathrm{mg}$ fumarate/g substrate DM $(600 \mathrm{mg}$ fumarate per fermenter). Fumarate was weighed and carefully mixed with the substrate immediately before this was placed into the nylon bags and fed to fermenters.

\section{Experimental procedure and sampling}

Two 18-d identical incubation runs were carried out independently, and experimental treatments were assigned randomly within each experimental run so that two fermenters received each of the treatments; each treatment was, therefore, conducted in quadruplicate. After $10 \mathrm{~d}$ adaptation, on days
$11,12,13$ and 14 samples for gas, VFA and ammonia-N determination were collected following the procedures described previously ${ }^{15}$. One nylon bag from each fermenter was collected daily, washed twice with $40 \mathrm{ml}$ fermenter's fluid, and then washed in the cold rinse cycle $(20 \mathrm{~min})$ of a washing machine. The DM apparent disappearance (DMD) after $48 \mathrm{~h}$ incubation was calculated from the loss in weight after oven drying at $60^{\circ} \mathrm{C}$ for $48 \mathrm{~h}$, and the residues were analyzed for NDF and ADF to estimate NDF and ADF disappearance (NDFD and ADFD, respectively).

On day 12 , a dose of $2.04 \mathrm{mg}{ }^{15} \mathrm{~N}\left(98 \%\right.$ enriched ${ }^{15} \mathrm{NH}_{4} \mathrm{Cl}$; Tracer S.A., Madrid, Spain) was added into each fermenter to instantaneously label the ammonia-N pool. A solution of ${ }^{15} \mathrm{NH}_{4} \mathrm{Cl}$ was then added to the artificial saliva at a rate of $4.00 \mathrm{mg}{ }^{15} \mathrm{~N} / \mathrm{g}$ substrate N. Microbial growth was measured on days 15 and 16 following the procedures described previously ${ }^{16}$. Briefly, for each fermenter, the total effluent for days 15 and 16 were mixed and homogenised. One portion $(300 \mathrm{~g})$ was frozen and lyophilised for determination of DM, non-ammonia $\mathrm{N}(\mathrm{NAN})$ and ${ }^{15} \mathrm{~N}$ enrichment; about $100 \mathrm{ml}$ were frozen for determination of ${ }^{15} \mathrm{~N}$ enrichment in ammonia-N, and the rest of the mix was used to isolate liquidassociated microbial pellets (LAM). The contents of the nylon bags removed on days 15 and 16 were used to determine the growth of solid-associated micro-organisms $(\mathrm{SAM})^{17}$. Microbial pellets were isolated by differential centrifugation ${ }^{15}$. The substrate was also analysed for their natural ${ }^{15} \mathrm{~N}$ content, and this value was used for background correction before ${ }^{15} \mathrm{~N}$ infusion.

On days 17 and 18, the substrate administered to each fermenter was distributed into three nylon bags, one containing $18 \mathrm{~g} \mathrm{DM}$, and two containing $4 \mathrm{~g}$ DM each. The two bags containing $4 \mathrm{~g}$ were removed after $6 \mathrm{~h}$ incubation, whereas the $18 \mathrm{~g} \mathrm{DM}$ bag remained for $48 \mathrm{~h}$ in the fermenters. One $4 \mathrm{~g}$ bag was washed as described above, and residues were analysed for NDF and ADF to estimate NDFD and ADFD. The other $4 \mathrm{~g}$ bag was washed, its content emptied, weighed and lyophilised to determine DM, NAN and ${ }^{15} \mathrm{~N}$ enrichment. On these days, $4 \mathrm{ml}$ of each fermenter fluid were taken both immediately before feeding and after $6 \mathrm{~h}$ incubation for VFA determination.

On day 17 , samples $(4 \mathrm{ml})$ of each fermenter fluid before feeding and of the liquid obtained from the first washing of the $6 \mathrm{~h}$ incubated bags were taken and immediately frozen at $-80^{\circ} \mathrm{C}$ for determination of enzymatic activities. After removing and washing the $6 \mathrm{~h}$ incubated bags, $1 \mathrm{ml}$ of each fermenter's fluid was diluted through a series of tubes containing $9.0 \mathrm{ml}$ anaerobic dilution solution ${ }^{18}$. Using the $10^{-6}$ through $10^{-11}$ dilution tubes, $1 \mathrm{ml}$ was placed in each of three tubes containing the Most Probable Number media ${ }^{19}$. Total and cellulolytic bacteria concentrations were determined according to the Most Probable Number procedure ${ }^{19}$.

Adaptative changes in the microbial population of fermenters to each treatment were studied using each fermenters' fluid as inoculum for batch cultures and measuring the response in the production of gas and $\mathrm{VFA}^{16}$. The fermentative activity of the fluid contained in each fermenter was tested against four pure substrates (Sigma-Aldrich Química S.A., Madrid, Spain): cellulose, oat spelt xylan, pectin from citrus peel and a mixture of starch $(40 \%$ wheat, $40 \%$ barley and $20 \%$ potato starch). On the last day of each incubation 
run, the two nylon bags present in each fermenter were removed, their content emptied and mixed with the effluent. The mixture was homogenised for $30 \mathrm{~s}$ with a blender and filtered through two layers of nylon cloth $(40 \mu \mathrm{m}$ pore size); then, $440 \mathrm{ml}$ filtrate were mixed with $110 \mathrm{ml}$ artificial saliva (enriched with $472 \mathrm{mg} \mathrm{NH}_{4} \mathrm{Cl}$ and $791 \mathrm{mg}$ trypticase per litre saliva), and $30 \mathrm{ml}$ of the final mixture were anaerobically dispensed to $120 \mathrm{ml}$ serum bottles containing $300 \mathrm{mg}$ of one of the substrates described earlier. Ten bottles (two bottles for each substrate and two bottles without substrate) were incubated per each fermenter. The bottles were capped and incubated at $39^{\circ} \mathrm{C}$ for $9 \mathrm{~h}$ for cellulose and for $6 \mathrm{~h}$ for the rest of substrates. The amount of gas produced was measured, the bottles were then opened and samples for VFA determination were taken.

\section{Effects of mixed enzymes on fibre content of substrate}

In order to investigate the effects of the $24 \mathrm{~h}$ pre-treatment with the enzyme preparation on NDF and ADF content of substrate, samples of substrate $(500 \mathrm{mg})$ were weighed into artificial fibre bags (\#F57 bags; $50 \times 40 \mathrm{~mm} ; 25 \pm 10 \mu \mathrm{m}$ pore size; ANKOM Technology Corporation, Macedon, NY, USA) and $1 \mathrm{ml}$ buffer solution $(\mathrm{CON})$ or $7.15 \mathrm{mg}$ of enzyme preparation was added into each bag. Bags were heat sealed, and kept at room temperature $\left(21-23^{\circ} \mathrm{C}\right)$ for $24 \mathrm{~h}$ before NDF and ADF analyses were conducted. This procedure was repeated five times.

\section{Analytical procedures}

Procedures for determination of DM, ash, N, NDF, ADF, VFA and ammonia-N have been reported previously ${ }^{15}$. An ANKOM $^{220}$ Fiber Analyzer unit (ANKOM Technology Corporation, Fairport, USA) was used for NDF and ADF analyses. The volume of gas produced was measured with a drum-type gas meter (model TG1; Ritter Apparatebaum GmbH, Bochum, Germany) and the concentration of methane was analyzed by gas chromatography ${ }^{15}$. Samples were prepared for ${ }^{15} \mathrm{~N}$ analysis ${ }^{15}$ and analyses of ${ }^{15} \mathrm{~N}$ enrichment were performed by isotope ratio mass spectrometry (VG Prism II, Middlewich, UK) connected in series to a DUMAS-style $\mathrm{N}$ analyzer (Model 1108, Carlo Erba Instruments, Milan, Italy).

For determination of enzymatic activities in rumen fluid samples, cells were lysed using a Mini-Beadbeater ${ }^{\mathrm{TM}}$ (BioSpec Products, Inc., Bartlesville, OK, USA) to release intracellular enzymes. The treatment consisted of three 60 -s pulses at $4^{\circ} \mathrm{C}$ using $0.1 \mathrm{~mm}$ zirconia beads. Unbroken cell material was removed by centrifugation $\left(10000 \mathrm{~g}, 10 \mathrm{~min}, 4^{\circ} \mathrm{C}\right)$ and the supernatant was used to analyze enzymatic activities (endoglucanase, exoglucanase, amylase and xylanase $)^{20}$.

\section{Calculations and statistical analyses}

The proportion of digesta NAN (liquid or solid) of microbial origin was estimated for each fermenter by dividing the ${ }^{15} \mathrm{~N}$ enrichment (atoms \% in excess) of the NAN portion of digesta by the enrichment of the corresponding microbial pellets (LAM or SAM). Daily microbial N production $(\mathrm{mg} / \mathrm{d}$; LAM or SAM) was estimated by multiplying total NAN production in the corresponding digesta (liquid or solid) by the proportion attributed to the microbes. Total daily microbial production was calculated as the sum of the flows of LAM and SAM. The amount of organic matter apparently fermented was estimated from net productions of acetate, propionate and butyrate $^{21}$. This value was used to estimate the efficiency of microbial growth (mg microbial N/g organic matter apparently fermented). The volume of gas produced in the fermenters (litres/d) was corrected for temperature $\left(0^{\circ} \mathrm{C}\right)$ and pressure $\left(1.013 \times 10^{5} \mathrm{~Pa}\right)$ conditions, and the amount of methane produced (mmol) was calculated by multiplying the gas produced by the methane concentration in the analysed sample.

The amounts of VFA produced in the batch cultures were obtained by subtracting the amounts present initially in the incubation medium from those determined at the end of the incubation period. Values of gas production in the batch cultures were corrected for the amount of gas produced in the bottles without substrate inoculated with the fluid from the corresponding fermenters.

Data relative to fermentation parameters were analysed as a split-plot design with additive treatment as the main-plot treatment and day of sampling as the subplot treatment. The model included additive treatment, incubation run, fermenter nested within additive treatment and day of sampling. Significance of additive treatment effects were tested using the variance between fermenters within treatment as the error term. Effects of other factors were tested against the residual error. In the analysis of data relative to microbial growth, microbial counts and enzymatic activities in the fermenters, and production of gas and VFA in batch cultures, day of sampling was excluded from the model. When a significant effect of additive treatment $(P \leq 0.05)$ was detected, differences between means were assessed by LSD test. All statistical analyses were conducted using the GLM procedure of the Statistical Analysis Systems statistical package version 8.02 (SAS Institute, Cary, NC, USA).

\section{Results}

Effects of mixed enzymes on fibre content of substrate

Compared to buffer-treated substrate, the treatment with FE reduced the NDF content (496 and $448 \mathrm{~g} / \mathrm{kg} \mathrm{DM}$, respectively; $P=0 \cdot 001$; SEM 6.2), although ADF content was unaffected (271 and $263 \mathrm{~g} / \mathrm{kg} \mathrm{DM} ; P=0 \cdot 266$; SEM 4.9).

\section{Effects of additives on rumen fermentation and microbial growth in Rusitec fermenters}

The experimental treatments did not affect either the daily amount of effluent $(586,581,591$ and $578 \mathrm{ml} / \mathrm{d}$ for $\mathrm{CON}$, FE, FUM and MIX, respectively; $P=0.951)$ or the $\mathrm{pH}$ of fermenters' contents before feeding $(6.56,6.58,6.61$ and 6.61 ; $P=0.881)$. The effects of additives on substrate apparent disappearance and daily production of VFA and methane are shown in Table 1. Compared to CON, both FE and MIX treatments increased $(P<0.05)$ DMD after $6 \mathrm{~h}$ of incubation by $21 \%$, but the increase was reduced to $6 \cdot 3$ and $6.1 \%$, respectively, after $48 \mathrm{~h}$ of incubation $(P<0 \cdot 05)$. Disappearance of $\mathrm{NDF}$ and ADF followed a similar pattern, since $\mathrm{FE}$ and MIX treatments increased $(P<0 \cdot 05)$ NDFD at $6 \mathrm{~h}$ by 22 and $16 \%$, compared to $\mathrm{CON}$, but the increase was reduced to $12 \%$ after $48 \mathrm{~h}$ incubation for both treatments. On the 
Table 1. Effect of experimental treatments on apparent disappearance of substrate dry matter (DMD), neutral-detergent fibre (NDFD) and acid-detergent fibre (ADFD) after 6 and $48 \mathrm{~h}$ incubation and daily production of VFA and methane in Rusitec fermenters*

\begin{tabular}{|c|c|c|c|c|c|c|}
\hline \multirow[b]{2}{*}{ Item } & \multicolumn{4}{|c|}{ Treatment $\dagger$} & \multirow[b]{2}{*}{ SEM } & \multirow[b]{2}{*}{$P$ value } \\
\hline & CON & FE & FUM & MIX & & \\
\hline \multicolumn{7}{|l|}{ Substrate disappearance (\%) } \\
\hline $\mathrm{DMD}$ at $6 \mathrm{~h}$ & $39.8^{\mathrm{a}}$ & $48 \cdot 2^{b}$ & $42 \cdot 2^{a}$ & $48 \cdot 2^{b}$ & 0.87 & $<0.001$ \\
\hline DMD at $48 \mathrm{~h}$ & $58 \cdot 6^{a}$ & $62 \cdot 3^{\mathrm{b}}$ & $58 \cdot 8^{\mathrm{a}}$ & $62 \cdot 2^{\mathrm{b}}$ & 0.75 & 0.043 \\
\hline NDFD at $6 \mathrm{~h}$ & $28 \cdot 8^{\mathrm{a}}$ & $35 \cdot 1^{b}$ & $28 \cdot 1^{\mathrm{a}}$ & $33.5^{\mathrm{b}}$ & 0.42 & $<0.001$ \\
\hline NDFD at $48 \mathrm{~h}$ & $36 \cdot 6^{a}$ & $40 \cdot 9^{b}$ & $36 \cdot 9^{a}$ & $41.0^{\mathrm{b}}$ & 0.74 & 0.001 \\
\hline ADFD at $6 \mathrm{~h}$ & $13 \cdot 8^{\mathrm{a}}$ & $19 \cdot 5^{\mathrm{b}}$ & $12 \cdot 9^{\mathrm{a}}$ & $17 \cdot 8^{\mathrm{b}}$ & 0.41 & $<0.001$ \\
\hline ADFD at $48 \mathrm{~h}$ & $28 \cdot 8^{\mathrm{a}}$ & $35 \cdot 1^{\mathrm{b}}$ & $28 \cdot 1^{\mathrm{a}}$ & $33.5^{\mathrm{b}}$ & 0.42 & $<0.001$ \\
\hline \multicolumn{7}{|l|}{ VFA production $(\mathrm{mmol} / \mathrm{d})$} \\
\hline Acetate & $30 \cdot 1^{\mathrm{a}}$ & $32 \cdot 8^{\mathrm{b}}$ & $33 \cdot 3^{\mathrm{b}}$ & $34 \cdot 4^{b}$ & 1.32 & 0.049 \\
\hline Propionate & $10 \cdot 3^{b}$ & $8.05^{\mathrm{a}}$ & $12 \cdot 7^{\mathrm{c}}$ & $10 \cdot 3^{\mathrm{b}}$ & 0.90 & 0.023 \\
\hline Butyrate & $11 \cdot 3^{\mathrm{a}}$ & $13 \cdot 4^{\mathrm{b}}$ & $11 \cdot 6^{\mathrm{a}}$ & $12 \cdot 8^{\mathrm{b}}$ & 0.73 & 0.041 \\
\hline Isobutyrate & $0.536^{a}$ & $0.738^{\mathrm{c}}$ & $0.544^{\mathrm{a}}$ & $0.617^{b}$ & 0.020 & $<0.001$ \\
\hline Valerate & $3.00^{\mathrm{a}}$ & $3.57^{\mathrm{b}}$ & $3.46^{\mathrm{b}}$ & $3.65^{\mathrm{b}}$ & 0.151 & 0.042 \\
\hline Isovalerate & 1.60 & 1.79 & 1.72 & 2.04 & 0.179 & 0.399 \\
\hline Total & $56 \cdot 8^{\mathrm{a}}$ & $60 \cdot 4^{\mathrm{ab}}$ & $63 \cdot 3^{\mathrm{b}}$ & $63 \cdot 8^{\mathrm{b}}$ & 2.92 & 0.041 \\
\hline Acetate:propionate (mol:mol) & $2 \cdot 92^{b}$ & $4.07^{d}$ & $2 \cdot 62^{\mathrm{a}}$ & $3.34^{\mathrm{c}}$ & 0.173 & $<0.001$ \\
\hline Methane $(\mathrm{mmol} / \mathrm{d})$ & $14 \cdot 1^{\mathrm{a}}$ & $16 \cdot 0^{\mathrm{b}}$ & $13 \cdot 2^{a}$ & $16 \cdot 2^{b}$ & 0.46 & 0.001 \\
\hline Methane:VFA (mol:mol) & $0.248^{b}$ & $0.265^{\mathrm{b}}$ & $0.208^{a}$ & $0.254^{b}$ & 0.0094 & 0.005 \\
\hline
\end{tabular}

${ }^{a, b, c}$ Mean values within a row with unlike superscript letter were significantly different $(P<0.05)$.

* Values are the mean of two daily observations in each of four fermenters for substrate disappearance after $6 \mathrm{~h}$ incubation $(n 8)$ and of four daily observations in each of four fermenters $(n 16)$ for the rest of the variables. Substrate was composed of grass hay and concentrate $(600$ and $400 \mathrm{~g} / \mathrm{kg} \mathrm{DM}$, respectively).

†CON: control (no additive); FE: 34.3, 0.57, 24.7 and 5.51 endoglucanase, exoglucanase, xylanase and amylase units, respectively, per g substrate DM; FUM: $30 \mathrm{mg}$ disodium fumarate/g substrate DM; MIX: FE treatment plus $30 \mathrm{mg}$ disodium fumarate/g substrate DM. Each fermenter received daily $20 \mathrm{~g}$ substrate DM.

contrary, there was no effect $(P>0.05)$ of FUM on DMD, NDFD and ADFD at any incubation time.

All experimental treatments increased daily production of acetate $(P=0 \cdot 049)$ and valerate $(P=0 \cdot 042)$. Compared to CON, FUM increased $(P<0.05)$ and FE reduced $(P<0.05)$ the production of propionate, but no differences $(P>0.05)$ were found for MIX. Butyrate production was augmented $(P<0.05)$ by 2.1 and $1.5 \mathrm{mmol} / \mathrm{d}$ for FE and MIX treatments, respectively, but no effect $(P>0.05)$ was detected for FUM. As a consequence of these changes, FE, FUM and MIX treatments increased total VFA production by $3.6,6.5$ and $7.0 \mathrm{mmol} / \mathrm{d}$, relative to $\mathrm{CON}$, but differences between $\mathrm{FE}$ and $\mathrm{CON}$ were not significant $(P>0 \cdot 05)$. The acetate:propionate ratio was lowest $(P<0.05)$ for FUM and greatest $(P<0.05)$ for FE, with CON and MIX having intermediate values. Compared to $\mathrm{CON}$, the treatment of substrate with FE and MIX increased $(P<0.05)$ the production of methane by 1.9 and $2.1 \mathrm{mmol} / \mathrm{d}$, whereas supplementing with FUM decreased it by $0.9 \mathrm{mmol} / \mathrm{d}(P>0.05)$.

Both FE and MIX treatments increased the daily flow of ammonia-N $(P<0 \cdot 001)$, relative to CON (Table 2$)$, but no differences $(P>0.05)$ between CON and FUM were found. The daily flow of total NAN was not affected $(P=0.339)$ by any experimental treatment, but microbial $\mathrm{N}$ flow was greater $(P=0.05)$ in FE and MIX fermenters, with no differences $(P>0.05)$ between CON and FUM. Whereas no differences $(P=0.969)$ between treatments were detected for SAM flow, both FE and MIX increased $(P<0.05)$ the flow of LAM compared to CON and FUM. Efficiency of microbial synthesis (mg microbial $\mathrm{N} / \mathrm{g}$ organic matter fermented) was not affected $(P=0.206)$ by any additive treatment.
The proportion of microbial $\mathrm{N}$ in the substrate residue after $48 \mathrm{~h}$ incubation was greater $(P<0.05)$ for FE and MIX than for CON, but no difference $(P>0 \cdot 05)$ was detected between CON and FUM (Table 2). In agreement with these results, the proportion of ${ }^{15} \mathrm{~N}$-ammonia incorporated in substrate residues after $6 \mathrm{~h}$ of incubation was greater $(P<0.05)$ for $\mathrm{FE}$ and MIX than for CON and FUM. Both FE and MIX treatments resulted in a significant $(P<0.05)$ increase in total bacteria numbers, but cellulolytic bacteria were unaffected $(P=0 \cdot 135)$.

As shown in Table 3 , greater $(P<0.05)$ endoglucanase, exoglucanase, amylase and xylanase activities were detected both in the fermenters' liquid content and in the liquid obtained from washing the 6-h incubated bags for FE and MIX fermenters, relative to $\mathrm{CON}$ ones, but no differences $(P>0.05)$ were found between CON and FUM treatments. Compared to CON, all additive treatments produced greater $(P<0.001)$ increases in total VFA concentrations during the first $6 \mathrm{~h}$ after feeding.

The results of the in vitro incubations with batch cultures are shown in Table 4. Batch cultures inoculated with rumen fluid from fermenters fed the enzyme-treated substrate (FE and MIX) produced greater $(P<0.01)$ amounts of both gas and VFA with cellulose, and greater $(P=0 \cdot 012)$ amounts of VFA with xylan. Compared to CON cultures, MIX treatment produced greater $(P<0.05)$ amounts of gas and VFA with pectin as substrate. On the contrary, there were no effects of additive treatments on production of VFA $(P=0 \cdot 208)$ and gas $(P=0 \cdot 120)$ for starch.

\section{Discussion}

In agreement with results from other studies ${ }^{22,23}$, the treatment with the enzyme preparation stimulated the initial phases of 
Table 2. Effect of the treatment with different additives on daily production of ammonia-N and non-ammonia- $N$ (NAN), daily $N$ flow of liquid-associated (LAM) and solid-associated microorganisms (SAM), efficiency of microbial synthesis (EMS) and microbial numbers in Rusitec fermenters ${ }^{\star}$

\begin{tabular}{|c|c|c|c|c|c|c|}
\hline \multirow[b]{2}{*}{ Item } & \multicolumn{4}{|c|}{ Treatment $\dagger$} & \multirow[b]{2}{*}{ SEM } & \multirow[b]{2}{*}{$P$ value } \\
\hline & CON & $\mathrm{FE}$ & FUM & MIX & & \\
\hline Ammonia- $\mathrm{N}(\mathrm{mg} / \mathrm{d})$ & $102^{\mathrm{a}}$ & $140^{\mathrm{b}}$ & $105^{\mathrm{a}}$ & $137^{\mathrm{b}}$ & $4 \cdot 0$ & $<0.001$ \\
\hline Total NAN (mg/d) & 217 & 230 & 226 & 226 & $5 \cdot 8$ & 0.339 \\
\hline Substrate NAN (mg/d) & $77 \cdot 0$ & $70 \cdot 4$ & 77.5 & $62 \cdot 7$ & 4.83 & 0.172 \\
\hline Microbial $\mathrm{N}$ flow (mg/d) & $140^{\mathrm{a}}$ & $162^{\mathrm{b}}$ & $149^{\mathrm{a}}$ & $164^{\mathrm{b}}$ & 4.8 & 0.018 \\
\hline LAM (mg/d) & $72 \cdot 0^{\mathrm{a}}$ & $92 \cdot 5^{\mathrm{bc}}$ & $79 \cdot 7^{\mathrm{ab}}$ & $95 \cdot 7^{\mathrm{c}}$ & $3 \cdot 88$ & 0.005 \\
\hline $\mathrm{SAM}(\mathrm{mg} / \mathrm{d})$ & $67 \cdot 7$ & $69 \cdot 5$ & 68.9 & $67 \cdot 8$ & $3 \cdot 10$ & 0.969 \\
\hline LAM (\% of total) & $51 \cdot 4^{\mathrm{a}}$ & $57 \cdot 1^{\mathrm{b}}$ & $53 \cdot 7^{\mathrm{a}}$ & $58 \cdot 6^{\mathrm{b}}$ & 1.68 & 0.050 \\
\hline SAM ( $\%$ of total) & $48 \cdot 5^{\mathrm{b}}$ & $42 \cdot 9^{\mathrm{a}}$ & $46 \cdot 3^{\mathrm{b}}$ & $41 \cdot 4^{\mathrm{a}}$ & 1.69 & 0.050 \\
\hline$\%$ microbial $\mathrm{N}$ in feed residue after $48 \mathrm{~h}$ of incubation & $53 \cdot 2^{\mathrm{a}}$ & $61.9^{\mathrm{b}}$ & $54 \cdot 5^{\mathrm{ab}}$ & $61 \cdot 5^{\mathrm{b}}$ & 2.58 & 0.049 \\
\hline Proportion of ${ }^{15} \mathrm{~N}$-ammonia in substrate residues after $6 \mathrm{~h}$ incubation & $0.045^{a}$ & $0.053^{\mathrm{b}}$ & $0.044^{\mathrm{a}}$ & $0.055^{\mathrm{b}}$ & 0.0021 & 0.010 \\
\hline EMS (mg microbial N/g OM fermented)‡ & $28 \cdot 0$ & $28 \cdot 8$ & $28 \cdot 1$ & 28.5 & $1 \cdot 11$ & 0.206 \\
\hline Total bacteria $\left(\times 10^{9} / \mathrm{ml}\right)$ & $2 \cdot 38^{\mathrm{a}}$ & $7 \cdot 00^{\mathrm{b}}$ & $3 \cdot 35^{\mathrm{a}}$ & $6 \cdot 03^{\mathrm{b}}$ & 1.041 & 0.046 \\
\hline Cellulolytic bacteria $\left(\times 10^{6} / \mathrm{ml}\right)$ & $2 \cdot 40$ & 8.05 & $2 \cdot 88$ & 8.00 & 3.537 & 0.135 \\
\hline
\end{tabular}

OM, organic matter.

a,b Mean values within a row with unlike superscripts letter were significantly different $(P<0.05)$.

*Values are the mean of four daily observations in each of four fermenters $(n 16)$ for ammonia- $\mathrm{N}$ and the mean of one observation in each of four fermenters ( $n 4)$ for the rest of the variables. Substrate was composed of grass hay and concentrate (600 and $400 \mathrm{~g} / \mathrm{kg} \mathrm{DM}$, respectively).

†CON: control (no additive); FE: 34.3, 0.57, 24.7 and 5.51 endoglucanase, exoglucanase, xylanase and amylase units, respectively, per g substrate DM; FUM: 30 mg of disodium fumarate/g substrate DM; MIX: FE treatment plus $30 \mathrm{mg}$ of disodium fumarate/g substrate DM. Each fermenter received daily $20 \mathrm{~g}$ substrate DM.

$\ddagger$ Organic matter (OM) apparently fermented was estimated from net production of acetate, propionate and butyrate as described by Demeyer ${ }^{21}$.

substrate degradation, but the effects were reduced as incubation time increased. It has been suggested ${ }^{22,24}$ that exogenous enzymes could increase fibre degradation through a hydrolytic action prior to feeding or in vitro incubation with rumen micro-organisms. In the present experiment, the treatment of substrate with FE reduced its NDF content, and similar effects have been previously reported for other fibre-degrading enzymes ${ }^{22,25}$. The treatment of substrate with the enzyme preparation increased significantly the disappearance of substrate after $48 \mathrm{~h}$ incubation, which contrasts with the general agreement that enzymes increased the rate, but not the extent, of feed degradation in the rumen ${ }^{26}$. As pointed out by Colombatto and co-workers ${ }^{2}, 48 \mathrm{~h}$ incubation cannot be considered as an end point for some substrates. In a later trial

Table 3. Effect of the treatment with different additives on enzymatic activities and on volatile fatty acid (VFA) concentrations after $6 \mathrm{~h}$ incubation in Rusitec fermenters

\begin{tabular}{|c|c|c|c|c|c|c|}
\hline \multirow[b]{2}{*}{ Item } & \multicolumn{4}{|c|}{ Treatment ${ }^{*}$} & \multirow[b]{2}{*}{ SEM } & \multirow[b]{2}{*}{$P$ value } \\
\hline & CON & $\mathrm{FE}$ & FUM & MIX & & \\
\hline \multicolumn{7}{|l|}{ Enzymatic activities $\dagger$} \\
\hline \multicolumn{7}{|l|}{ Rumen fluid } \\
\hline Endoglucanase & $128^{\mathrm{a}}$ & $503^{b}$ & $129^{a}$ & $473^{b}$ & 23.0 & $<0.001$ \\
\hline Exoglucanase & $18 \cdot 6^{\mathrm{a}}$ & $25 \cdot 3^{\mathrm{b}}$ & $17 \cdot 3^{\mathrm{a}}$ & $23 \cdot 1^{\mathrm{b}}$ & $1 \cdot 19$ & 0.002 \\
\hline Amylase & $397^{a}$ & $1180^{\circ}$ & $477^{\mathrm{ab}}$ & $804^{\mathrm{bc}}$ & $128 \cdot 8$ & 0.048 \\
\hline Xylanase & $471^{a}$ & $3048^{b}$ & $515^{\mathrm{a}}$ & $2967^{\mathrm{b}}$ & $140 \cdot 9$ & $<0.001$ \\
\hline \multicolumn{7}{|l|}{ Washing liquid } \\
\hline Endoglucanase & $57 \cdot 0^{\mathrm{a}}$ & $656^{\mathrm{b}}$ & $66 \cdot 5^{\mathrm{a}}$ & $627^{\mathrm{b}}$ & 21.9 & $<0.001$ \\
\hline Exoglucanase & $18 \cdot 1^{a}$ & $28 \cdot 1^{\mathrm{b}}$ & $16 \cdot 2^{a}$ & $26 \cdot 0^{b}$ & 1.45 & 0.001 \\
\hline Amylase & $104^{a}$ & $1126^{\mathrm{b}}$ & $176^{a}$ & $1078^{\mathrm{b}}$ & $138 \cdot 5$ & $<0.001$ \\
\hline Xylanase & $299^{a}$ & $3304^{b}$ & $301^{a}$ & $3085^{b}$ & $163 \cdot 8$ & $<0.001$ \\
\hline \multicolumn{7}{|l|}{$\operatorname{VFA}(\mathrm{mmol} / \mathrm{l}) \ddagger$} \\
\hline Acetate & $12 \cdot 7^{\mathrm{a}}$ & $18 \cdot 5^{\mathrm{b}}$ & $18 \cdot 1^{\mathrm{b}}$ & $17 \cdot 5^{\mathrm{b}}$ & $1 \cdot 10$ & 0.003 \\
\hline Propionate & $4 \cdot 70^{\mathrm{a}}$ & $5 \cdot 77^{\mathrm{b}}$ & $9 \cdot 61^{c}$ & $10 \cdot 2^{c}$ & 0.310 & $<0.001$ \\
\hline Butyrate & $4 \cdot 73^{\mathrm{a}}$ & $10 \cdot 4^{b}$ & $5 \cdot 66^{\mathrm{a}}$ & $8.90^{\mathrm{b}}$ & 0.744 & 0.001 \\
\hline Total & $24 \cdot 6^{\mathrm{a}}$ & $39 \cdot 2^{\mathrm{b}}$ & $36 \cdot 5^{\mathrm{b}}$ & $39.7^{\mathrm{a}}$ & 1.51 & $<0.001$ \\
\hline
\end{tabular}

a,b,c Mean values within a row with unlike superscripts letter were significantly different $(P<0.05)$.

${ }^{*} \mathrm{CON}$ : control (no additive); FE: 34.3, 0.57, 24.7 and 5.51 endoglucanase, exoglucanase, xylanase and amylase units respectively, per g substrate DM; FUM: $30 \mathrm{mg}$ disodium fumarate/g substrate DM; MIX: FE treatment plus $30 \mathrm{mg}$ disodium fumarate/g substrate DM. Each fermenter received daily $20 \mathrm{~g}$ substrate DM.

†Endoglucanase, exoglucanase and amylase activities are expressed as nanomol glucose liberated per min and $\mathrm{ml}$ of sample at $39^{\circ} \mathrm{C}$ and $\mathrm{pH} 6.5$ using carboxymethylcellulose, Avicel $\mathrm{PH}-101$ and soluble starch as substrate, respectively. Xylanase activity is expressed as nanomol xylose liberated from oat spelt xylan per min and $\mathrm{ml}$ of sample at $39^{\circ} \mathrm{C}$ and $\mathrm{pH}$ 6.5. Rumen fluid was sampled before feeding and the washing liquid was obtained from washing the 6-h incubated bags into the fermenters. Values are the mean of four observations.

$\ddagger$ Calculated for each fermenter as the VFA concentration in rumen fluid at $6 \mathrm{~h}$ after feeding minus the VFA concentration measured immediately before feeding. 
Table 4. Production of gas and volatile fatty acids (VFA) in batch cultures containing $300 \mathrm{mg}$ different substrates (cellulose, xylan, pectin and starch) inoculated with fluid from Rusitec fermenters fed a grass hay: concentrate substrate (600 and $400 \mathrm{~g} / \mathrm{kg} \mathrm{DM}$, respectively) after being treated with different additives

(Mean values of eight fermentations)*

\begin{tabular}{|c|c|c|c|c|c|c|}
\hline \multirow[b]{2}{*}{ Substrate and item } & \multicolumn{4}{|c|}{ Treatment† } & \multirow[b]{2}{*}{ SEM } & \multirow[b]{2}{*}{$P$ value } \\
\hline & CON & $\mathrm{FE}$ & FUM & MIX & & \\
\hline \multicolumn{7}{|l|}{ Cellulose } \\
\hline Gas ( $\mu \mathrm{mol})$ & $0.169^{a}$ & $0.518^{c}$ & $0.263^{b}$ & $0.563^{c}$ & 0.0470 & $<0.001$ \\
\hline VFA ( $\mu \mathrm{mol})$ & $551^{a}$ & $798^{b}$ & $554^{a}$ & $795^{\mathrm{b}}$ & $44 \cdot 7$ & $<0.001$ \\
\hline \multicolumn{7}{|l|}{ Xylan } \\
\hline Gas $(\mu \mathrm{mol})$ & 0.361 & 0.408 & 0.337 & 0.415 & 0.0510 & 0.661 \\
\hline VFA ( $\mu \mathrm{mol})$ & $899^{a}$ & $1080^{\mathrm{b}}$ & $842^{a}$ & $1143^{\mathrm{b}}$ & $60 \cdot 0$ & 0.012 \\
\hline \multicolumn{7}{|l|}{ Pectin } \\
\hline Gas ( $\mu \mathrm{mol})$ & $0.585^{a}$ & $0.763^{\mathrm{ab}}$ & $0.741^{a}$ & $0.942^{b}$ & 0.0693 & 0.011 \\
\hline VFA ( $\mu \mathrm{mol})$ & $926^{a}$ & $991^{a}$ & $961^{a}$ & $1311^{\mathrm{b}}$ & $56 \cdot 0$ & $<0.001$ \\
\hline \multicolumn{7}{|l|}{ Starch } \\
\hline Gas ( $\mu \mathrm{mol})$ & 1.054 & 1.027 & $1 \cdot 134$ & $1 \cdot 246$ & 0.0777 & 0.120 \\
\hline VFA ( $\mu \mathrm{mol})$ & 1111 & 1012 & 1030 & 1186 & $62 \cdot 9$ & 0.208 \\
\hline
\end{tabular}

${ }^{a, b, c}$ Mean values within a row with unlike superscripts letter were significantly different $(P<0.05)$.

${ }^{*}$ Cellulose was incubated for $9 \mathrm{~h}$, and the rest of the substrates for $6 \mathrm{~h}$.

†CON: control (no additive); FE: 34.3, 0.57, 24.7 and 5.51 endoglucanase, exoglucanase, xylanase and amylase units, respectively, per g substrate DM; FUM: $30 \mathrm{mg}$ disodium fumarate/g substrate DM; MIX: FE treatment plus $30 \mathrm{mg}$ disodium fumarate/g substrate DM. Each fermenter received daily $20 \mathrm{~g}$ substrate DM.

conducted at our laboratory, the in situ degradation of substrate in the rumen of sheep was measured, and substrate DMD after $48 \mathrm{~h}$ incubation in Rusitec fermenters (58.6\%) represented about $71 \%$ of its potential DM degradability $(82.5 \%$; LA Giraldo et al., unpublished results).

The increase in substrate degradability produced by FE and MIX treatments is in accordance with the greater VFA production observed in the fermenters fed the enzyme-treated substrate. After $6 \mathrm{~h}$ incubation, the increase in total VFA concentration in rumen fluid was, relative to that in CON fermenters, $14.6,11.9$ and $15.1 \mathrm{mmol} / \mathrm{l}$ greater in FE, FUM and MIX fermenters, respectively. Since all fermenters had similar liquid volumes and dilution rates, these results would indicate that all additives stimulated VFA production during the first $6 \mathrm{~h}$ of incubation. The increased VFA production in FE and MIX fermenters was probably due to the enhanced substrate degradability, since DMD at $6 \mathrm{~h}$ was increased by 8.4 percentage units, relative to CON. In contrast, no significant effects of FUM on DMD at $6 \mathrm{~h}$ incubation were found, although DMD in FUM was 2.4 percentage units greater. This would suggest that the observed increase in VFA concentrations was mainly due to fermentation of fumarate itself, since fumarate can be converted into propionate and acetate by different rumen micro-organisms ${ }^{27}$. If a mean liquid volume of $500 \mathrm{ml}$ for each fermenter is assumed (volumes were measured on the last day of each incubation run), the increase in total VFA from 0 to $6 \mathrm{~h}$ after feeding would be $6.0 \mathrm{mmol}$ greater in FUM than in CON fermenters. Since on days 17 and 18 each fermenter received daily $4.88 \mathrm{mmol}$ fumarate, the results would indicate that all fumarate was fermented during the first $6 \mathrm{~h}$ incubation. In agreement with this hypothesis, it has been reported that $192 \mathrm{mg}$ fumarate were completely consumed by mixed rumen micro-organisms in batch cultures $(60 \mathrm{ml}$ volume) after $6 \mathrm{~h}$ incubation ${ }^{27}$.

When comparing the increases in VFA concentrations after $6 \mathrm{~h}$ incubation, it was observed that there were no differences between FE, FUM and MIX treatments (39.2, 36.5 and
$39.7 \mathrm{mmol} / \mathrm{l}$, respectively). Since MIX fermenters were treated with both additives, it would be expected that the increases in VFA concentrations were greater in these fermenters than in FE or FUM ones. The reasons for the lack of differences are unknown, but the results would indicate that FE and FUM did not act synergistically to increase VFA production. The observed increases in propionate concentration at $6 \mathrm{~h}$ incubation in FUM and MIX fermenters were similar, but were greater than those in FE fermenters (9.61, 10.2 and $5.77 \mathrm{mmol} / 1$, respectively). This would again indicate that fumarate was rapidly fermented, since FE treatment decreased significantly the daily production of propionate compared to the rest of experimental treatments.

Treating the substrate with FE increased the daily production of acetate and butyrate, but decreased propionate production, thus indicating a change in fermentation pattern. Similar changes have been reported by treating the substrate fed to continuous culture fermenters with a commercial enzyme produced by $T$. longibrachiatum ${ }^{28}$, and it has been suggested that changes in fermentation pattern may reflect a shift in the species profile of colonising bacteria in response to pre-treatment of feed with exogenous enzymes ${ }^{1}$. The change in VFA pattern in our study is consistent with the greater methane production and fibre degradation observed in the enzyme-treated fermenters, since acetate and butyrate production is associated with the release of $\mathrm{H}_{2}$ which can be used by methanogens to form methane ${ }^{29}$. All these effects would indicate a greater activity of fibre-degrading bacteria in FE fermenters, which is supported by the greater xylanase, endoglucanase and exoglucanase activities observed in their rumen fluid. In addition, numbers of cellulolytic bacteria were 3.3 times greater in $\mathrm{FE}$ than in $\mathrm{CON}$ fermenters, although differences were not significant $(P>0.05)$. Since only the fermenters' fluid was used to inoculate the Most Probable Number culture tubes, any effect of FE on SAM population could not have been detected. Both LAM and the non-adherent micro-organisms washed out of the substrate (nylon bags 
were washed twice with $40 \mathrm{ml}$ of fermenters' fluid and the washing liquid was returned to the fermenters before using the fluid as inoculum for the Most Probable Number cultures) should have been present in the fermenters' fluid as inoculum, but not SAM. In contrast, the inoculum used for batch cultures should have included partially SAM, since it was prepared by mixing the rumen fluid from each fermenter with the corresponding substrate residues, followed by homogenising and filtering. Homogenising has been used as a method to detach $\mathrm{SAM}^{30}$, and a greater activity of SAM in the inoculum from FE and MIX fermenters could explain the enhanced VFA production observed in the batch cultures with cellulose and xylan as substrates and inoculated with rumen fluid from these fermenters, relative to $\mathrm{CON}$ ones.

A mechanism proposed as a possible mode of action of fibrolytic enzymes in the rumen is to stimulate the attachment of rumen micro-organisms to feed particles ${ }^{31}$. To evaluate this possibility, nylon bags with substrate were incubated for $6 \mathrm{~h}$ and the ${ }^{15} \mathrm{~N}$ enrichment in substrate residues was determined. Since substrate residues were washed, dried and treated with $\mathrm{NaOH}(\mathrm{pH}>10)$ to eliminate ammonia- $\mathrm{N}^{32},{ }^{15} \mathrm{~N}$ incorporation should be exclusively from SAM origin. The greater incorporation of ${ }^{15} \mathrm{~N}$ in substrate residues (calculated by dividing the ${ }^{15} \mathrm{~N}$ enrichment in substrate residues by the ${ }^{15} \mathrm{~N}$ enrichment of ammonia-N) in FE and MIX fermenters, compared to $\mathrm{CON}$ ones, would indicate that enzyme treatment stimulated the initial phases of microbial colonisation. In addition, the proportion of microbial $\mathrm{N}$ in substrate residues after $48 \mathrm{~h}$ incubation was greater for FE and MIX treatments than for CON, thus indicating a greater colonisation of feed particles after a long incubation period. In agreement with these results, it has been reported that treating a 0.5:0.5 alfalfa hay:barley grain substrate with exogenous xylanase increased ${ }^{15} \mathrm{~N}$ incorporation into SAM-N after 24 and $48 \mathrm{~h}$ incubation in a Rusitec system ${ }^{1}$.

Although the proportion of microbial $\mathrm{N}$ in substrate residues after $48 \mathrm{~h}$ incubation was greater for FE and MIX than for CON fermenters, the daily flow of SAM did not differ between treatments. This was due to the lower amount of substrate residues recovered for FE and MIX after $48 \mathrm{~h}$ incubation, as a consequence of increased substrate degradation. On the contrary, the treatment of substrate with enzyme increased LAM flow. This microbial fraction is composed of micro-organisms located in free suspension or loosely associated with feed particles, and therefore they are not expected to ferment structural carbohydrates. It is possible that the treatment with the enzyme preparation produced a greater amount of secondary products derived from structural carbohydrates, which entered the liquid pool and stimulated LAM growth. In agreement with these results, it has been reported that treating the diet of dairy cows with a commercial product from $T$. longibrachiatum increased the numbers of rumen bacteria that utilise hemicellulose or secondary products of cellulose digestion ${ }^{33}$. The greater LAM growth in our study is in accordance with the observed increase in enzymatic activities in the rumen fluid from FE and MIX fermenters. The enzyme preparation used in this experiment presented mainly endoglucanase and xylanase activities, but it seems unlikely that the observed increase in these enzymatic activities in rumen fluid was due to a direct effect of the enzyme preparation. Since the enzyme preparation was applied onto the substrate $24 \mathrm{~h}$ before being placed into the fermenters, probably little intact enzymes remained at the start of fermentation. In addition, enzymatic activities in rumen fluid were measured in samples taken $24 \mathrm{~h}$ after feeding, and after this incubation time possibly the enzymes had been completely fermented by the rumen micro-organisms. Moreover, enhanced cellulase and xylanase activities in rumen fluid produced by the treatment of feed with exogenous fibrolytic enzymes have been reported in in vitro ${ }^{1,25}$ and in vivo studies ${ }^{34,35}$, and Morgavi et al. $^{36}$ demonstrated synergism between exogenous enzymes produced by $T$. longibrachiatum and those produced by rumen micro-organisms such that the net combined hydrolytic effect in the rumen was much greater than that estimated from the individual activities.

Methane:VFA ratios were in the range of values previously reported for fermentation of similar diets in a Rusitec system $^{37}$, and were not affected by FE and MIX treatments, but were decreased by FUM. In contrast to the marked effects of FE treatment on rumen fermentation, the treatment with FUM produced only few changes on rumen variables. Compared to CON, FUM treatment increased the production of acetate, propionate and total VFA, but failed to increase substrate disappearance or to reduce methane production, as has been reported in previous studies ${ }^{8-10}$. The reasons for the lack of effects of FUM may be related to the dose of fumarate and the nature of the incubated substrate ${ }^{10,38}$. López et al. ${ }^{8}$ reported that methane production decreased by $17 \%$ $(1.3 \mathrm{mmol} / \mathrm{d} ; P=0.017)$ and acetate and propionate production augmented by $3.5(P=0.182)$ and $4.9(P=0.003) \mathrm{mmol} / \mathrm{d}$, respectively, when Rusitec fermenters fed a $0 \cdot 5: 0.5$ grass hay: concentrate substrate were supplemented daily with $6.25 \mathrm{mmol}$ fumarate. In the present study each fermenter received daily $3.75 \mathrm{mmol}$ fumarate, and methane production was decreased by $6.4 \%(0.9 \mathrm{mmol} / \mathrm{d} ; P>0.05)$ and acetate and propionate production augmented by 3.2 and $2.4 \mathrm{mmol} / \mathrm{d}$, respectively $(P<0.05)$. Since in both studies fermenters were supplied daily with $20 \mathrm{~g}$ substrate, in the study of López et al. ${ }^{8}$ fumarate represented $5 \%$ of substrate, compared with $3 \%$ in the present study. The decision to supplement the fermenters with a lower dose of fumarate was taken based on previous results, since García-Martínez et al. ${ }^{10}$ did not find differences between the effects of 4 and $8 \mathrm{~mm}$ fumarate on fermentation of three different substrates in batch cultures of mixed rumen micro-organisms $(3.75 \mathrm{mmol} / \mathrm{d}$ represented a final concentration of $6.25 \mathrm{~mm}$ in our fermenters). Comparison of our results to those of López et al. ${ }^{8}$ seems to indicate that a greater amount of fumarate than that used in our study would be necessary to modify rumen populations, and thus, substrate fermentation in Rusitec fermenters. In our study FUM treatment did not affect bacterial numbers, whereas López et al. ${ }^{8}$ reported a significant increase in both total and cellulolytic bacteria by supplementing with fumarate.

The results of the present study indicate that the use of FE as feed additive had a stimulatory effect on rumen fermentative activity. Treating the substrate with the enzyme preparation altered the fibre structure of substrate and increased its microbial colonisation, resulting in enhanced fibre degradation, VFA and methane production, and growth and enzymatic activities of rumen micro-organisms. Supplementing with fumarate increased VFA production and reduced slightly methane production, but these effects seem to be mainly due to fumarate fermentation itself. Finally, the lack of differences 
between FE and MIX treatments in most of the measured variables would indicate that at the dose used in this study, fumarate did not further improve rumen fermentation, compared to the use of FE alone. Studies with greater amounts of fumarate are necessary to confirm the hypothesis that fibrolytic enzymes and fumarate could act synergistically to improve rumen fermentation, since observed effects of both additives seem to be complementary.

\section{Acknowledgements}

The authors acknowledge the financial support received from the CICYT (Project AGL2001-0130) and Junta de Castilla y León (Project LE040A05). L. A. Giraldo gratefully acknowledges receipt of a grant from the Fundación Carolina.

\section{References}

1. Wang Y, McAllister TA, Rode LM, Beauchemin KA, Morgavi DP, Nsereko VL, Iwaasa AD \& Yang W (2001) Effects of an exogenous enzyme preparation on microbial protein synthesis, enzyme activity and attachment to feed in the Rumen Simulation Technique (Rusitec). Br J Nutr 85, 325-332.

2. Colombatto D, Morgavi DP, Furtado AF \& Beauchemin KA (2003) Screening of exogenous enzymes for ruminant diets: Relationships between biochemical characteristics and in vitro degradation. J Anim Sci 81, 2628-2638.

3. Dong Y, Bae HD, McAllister TA, Mathison GW \& Cheng KJ (1999) Effects of exogenous fibrolytic enzymes, $\alpha$-bromoethanesulfonate and monensin on fermentation in a rumen simulation (Rusitec) system. Can J Anim. Sci 79, 491-498.

4. Giraldo LA, Tejido ML, Ranilla MJ \& Carro MD (In the Press) Effects of exogenous cellulase supplementation on microbial growth and ruminal fermentation of a high-forage diet in Rusitec fermenters. J Anim Sci.

5. Giraldo LA, Tejido ML, Ranilla MJ \& Carro MD (In the Press) Effects of exogenous fibrolytic enzymes on in vitro rumen fermentation of substrates with different forage:concentrate ratios. Anim Feed Sci Technol.

6. Moss AR, Jouany JP \& Newbold J (2000) Methane production by ruminants: its contribution to global warming. Ann Zootech 49, 231-253.

7. Demeyer DI \& Fievez V (2000) Ruminants et environnement: la méthanogenèse (Ruminants and environment: methanogenesis). Ann Zootech 49, 95-112.

8. López S, Valdés C, Newbold CJ \& Wallace RJ (1999) Influence of sodium fumarate addition on rumen fermentation in vitro. $\mathrm{Br}$ J Nutr 81, 59-64.

9. Carro MD \& Ranilla MJ (2003) Influence of different concentrations of disodium fumarate on methane production and fermentation of concentrate feeds by rumen microorganisms in vitro. Br J Nutr 90, 617-623.

10. García-Martínez R, Ranilla MJ, Tejido ML \& Carro MD (2005) Effects of disodium fumarate on in vitro rumen microbial growth, methane production and fermentation of diets differing in their forage:concentrate ratio. Br J Nutr 94, 71-77.

11. Czerkawski JW \& Breckenridge G (1977) Design and development of a long-term rumen simulation technique (Rusitec). $\mathrm{Br} J$ Nutr 38, 371-384.

12. Carro MD, Lebzien P \& Rohr K (1992) Influence of yeast culture on the in vitro fermentation (Rusitec) of diets containing variable portions of concentrates. Anim Feed Sci Technol 37, 209-220.

13. McDougall EI (1948) Studies on ruminant saliva. I. The composition and output of sheep's saliva. Biochem J 43, 99-109.
14. Giraldo LA, Ranilla MJ, Tejido ML \& Carro MD (2004) Effect of enzyme application method on in vitro rumen fermentation of tropical forages. J Anim Feed Sci 13, 63-66.

15. Carro MD \& Miller EL (1999) Effect of supplementing a fibre basal diet with different nitrogen forms on ruminal fermentation and microbial growth in an in vitro semicontinuous culture system (RUSITEC). Br J Nutr 82, 149-157.

16. Gómez JA, Tejido ML \& Carro MD (2005) Mixed rumen micro-organisms growth and rumen fermentation of two diets in RUSITEC fermenters: influence of disodium malate supplementation. Br J Nutr 93, 479-484.

17. Ranilla MJ \& Carro MD (2003) Diet and procedures to detach particle-associated microbes from ruminal digesta influence chemical composition of microbes and estimation of microbial growth in Rusitec fermenters. J Anim Sci 81, 537-544.

18. Dehority BA (1969) Pectin-fermenting bacteria isolated from the bovine rumen. J Bacteriol 99, 189-196.

19. Dehority BA, Tirabasso PA \& Grifo AP Jr. (1989) Most probable-number procedures for enumerating ruminal bacteria, including the simultaneous estimation of total bacteria and cellulolytic numbers in one medium. Appl Environ Microbiol 55, 2789-2792.

20. Colombatto D \& Beauchemin KA (2003) A proposed methodology to standarize the determination of enzymatic activities present in enzyme additives used in ruminant diets. Can $J$ Anim Sci 83, 559-568.

21. Demeyer DI (1991) Quantitative aspects of microbial metabolism in the rumen and hindgut. In Rumen microbial metabolism and ruminant digestion, pp. 217-237 [JP Jouany, editor]. Paris: INRA Editions.

22. Nsereko VL, Morgavi DP, Rode LM, Beauchemin KA \& McAllister TA (2000) Effects of fungal enzyme preparations on hydrolysis and subsequent degradation of alfalfa hay fiber by mixed rumen microorganisms in vitro. Anim Feed Sci Technol 88, 153-170.

23. Colombatto D, Mould FL, Bhat MK, Morgavi DP, Beauchemin KA \& Owen E (2003) Influence of fibrolytic enzymes on the hydrolysis and fermentation of pure cellulose and xylan by mixed ruminal microorganisms in vitro. J Anim Sci 81, 1040-1050.

24. Wallace RJ, Wallace SJA, McKain N, Nsereko VL \& Hartnell GF (2001) Influence of supplementary fibrolytic enzymes on the fermentation of corn and grass silages by mixed ruminal microorganisms in vitro. J Anim Sci 79, 1905-1916.

25. Colombatto D, Hervás G, Yang WZ \& Beauchemin KA (2003) Effects of enzyme supplementation of a total mixed ration on microbial fermentation in continuous culture, maintained at high and low pH. J Anim Sci 81, 2617-2627.

26. Beauchemin KA, Morgavi DP, McAllister TA, Yang WZ \& Rode LM (2001) The use of feed enzymes in ruminant diets. In Recent Advances in Animal Nutrition, pp. 297-322 [PC Garnsworthy and PJ Wiseman, editors]. Notthingham: Nottingham University Press.

27. Asanuma N, Iwamoto M \& Hino T (1999) Effect of the addition of fumarate on methane production by ruminal microorganisms in vitro. J Dairy Sci 82, 780-787.

28. Yang WZ, Beauchemin KA \& Vedres DD (2002) Effects of pH and fibrolytic enzymes on digestibility, bacterial protein synthesis, and fermentation in continuous culture. Anim Feed Sci. Technol. 102, 137-150.

29. Stewart CS, Flint HJ \& Bryant MP (1997) The rumen bacteria. In The Rumen Microbial Ecosystem, pp. 10-72 [PN Hobson and CS Stewart, editors]. London: Chapman and Hall.

30. Carro MD \& Miller EL (2002) Comparison of microbial markers $\left({ }^{15} \mathrm{~N}\right.$ and purine bases) and bacterial isolates for the 
determination of rumen microbial protein synthesis. Anim Sci 75, 315-321.

31. Newbold J (1997) Proposed mechanisms for enzymes as modifiers of ruminal fermentation. In Proceedings of the 8th Annual Florida Ruminant Nutrition Symposium, pp. 146-159. University of Florida, Gainesville, Florida.

32. Firkins JL, Berger LL, Merchen NR, Fahey GC Jr \& Mulvaney RL (1992) Ruminal nitrogen metabolism in steers as affected by feed intake and dietary urea concentration. J Dairy Sci 70, 2302-2314.

33. Nsereko VL, Beauchemin KA, Morgavi DP, Rode LM, Furtado AF, McAllister TA, Iwaasa AD, Wang WZ \& Wang Y (2002) Effect of a fibrolytic enzyme preparation from Trichoderma longibrachiatum on the rumen microbial population of dairy cows. Can J Microbiol 48, 14-20.

34. Yang WZ, Beauchemin KA \& Rode LM (1999) Effects of enzymes feed additives on extent of digestion and milk production of lactating dairy cows. J Dairy Sci 82, 391-403.
35. Hristov AN, McAllister TA \& Cheng KJ (2000) Intraruminal supplementation with increasing levels of exogenous polysaccharide-degrading enzymes: effects on nutrient digestion in cattle fed barley grain diets. J Anim Sci 78, 477-487.

36. Morgavi DP, Beauchemin KA, Nsereko VL, Rode LM, Iwaasa AD, Yang WZ, McAllister TA \& Wang Y (2000) Synergy between the ruminal fibrolytic enzymes and enzymes from Trichoderma longibrachiatum. $J$ Dairy Sci 83, 1310-1321.

37. Czerkawski JW \& Breckenridge G (1979) Experiments with the long term rumen simulation technique (Rusitec): response to supplementation of basal rations. Br J Nutr 42, 217-228.

38. Newbold CJ, López S, Nelson N, Ouda JO, Wallace RJ \& Moss AR (2005) Propionate precursors and other metabolic intermediates as possible alternative electron acceptors to methanogenesis in ruminal fermentation. Br J Nutr 94, $27-35$. 